\title{
Ultrasensitive $\mathrm{RGO} / \mathrm{Cu}_{2} \mathrm{O}$ film synthetized by hydrothermal method to detect $\mathrm{NO}_{2}$ gas at room temperature
}

\author{
Xiangyi Zhu, Yongcai Guo*, Yong Zhou \\ Key Laboratory of Optoelectronic Technology and Systems of Ministry of Education, College of \\ Optoelectronic Engineering, Chongqing University, Chongqing, China. \\ Corresponding author's e-mail address: ycguo@cqu.edu.cn
}

\begin{abstract}
Advancing researches had been focused on incorporating RGO with metal oxidize to improve the gassensing sensitivity. In this paper, a neural-like $\mathrm{RGO} / \mathrm{Cu}_{2} \mathrm{O}$ composites was synthetized with a facile hydrothermal method. two crystalline morphology nanoparticles and nanowires existed as one integral morphology. The materials' ultrasensitive property could achieve nearly $35 \%$ at 50 ppb $\mathrm{NO}_{2}$ level at room temperature. Chemical reaction factors such as temperature, $\mathrm{PH}$, ions concentration (reactant and reductant included) had been considered to influence morphologies and conductivities of products. Different characterization techniques, including TEM, FESEM, XRD, XPS, BET, Raman Spectrum, were employed to explore the sensing mechanism. In addition, gas sensing measurements of sensitivity, stability, repeatability and selectivity also be tested, which indicated the $\mathrm{RGO} / \mathrm{Cu}_{2} \mathrm{O}$ composites an excellent candidate for trace $\mathrm{NO}_{2}$ detection with promising prospect.
\end{abstract}

Key words: reduced graphene oxide; cuprous oxide; nitrogen dioxide; room temperature; 